\title{
Factorial Structure of the Self-Report Barriers for Practice Physical Exercise in Mexican Athletes University Students
}

\author{
Dr. Juan Francisco Aguirre Chavez, \\ Dr. Perla Jannet Jurado Garcia, \\ Dr. Susana Ivonne Aguirre Vasquez, \\ Dr. Jose Rene Blanco Ornelas, \\ Autonomous University of Chihuahua, Mexico
}

Doi: 10.19044/esj.2018.v14n12p25 URL:http://dx.doi.org/10.19044/esj.2018.v14n12p25

\begin{abstract}
The present study intends to investigate if the psychometric results are replicated for the Self-Report of Barriers to the Practice of Physical Exercise (ABPEF) in Mexican athletes university students. A total of 651 university students participated (mean age $=20.8 \pm 2.4$ years). The factorial structure of the questionnaire was analyzed through confirmatory factor analyzes, which showed that a structure of four factors is viable and adequate. The four factors (body image, fatigue, obligations and environment), based on statistical and substantive criteria, have shown adequate fit indicators of reliability and validity. In addition, the results of the factorial analyzes carried out with the sub-samples indicate the existence of strong evidence of the stability of the factorial structure. Future research should replicate these findings in larger samples.
\end{abstract}

Keywords: Instrumental study; factorial structure; construct validation; factorial invariance

\section{Introduction}

At present, there is conclusive evidence that regular physical activity substantially improves the physical condition and health status of children, youth and adults. In comparison with their sedentary counterparts, those who do some type of regular exercise show a better cardiorespiratory fitness, and greater muscular endurance. In addition, it is sufficiently documented that they present lower body fat, a more favorable risk profile of cardiovascular and metabolic disease, better bone health, and a lower presence of symptoms of anxiety and depression, which is related to a better general health condition 
(Castañeda-Vázquez, Campos, \& Del Castillo, 2016, World Health Organization, 2010).

This international organization (WHO), recommends for college-aged people and adults up to 64 years, 150 minutes per week, at least, of moderate aerobic physical activity, or 75 minutes of vigorous aerobic physical activity, or an equivalent combination of moderate activities and vigorous, without neglecting the work of muscular strength.

But in a study conducted in Spain was found that slightly more than $50 \%$ of college students who participated, is below these international recommendations for healthy physical activity.

Likewise, an association was found between gender and levels of physical activity, with men reflectixng to be more physically active than women and they obtain a greater degree of compliance with the recommendations of physical activity practice. In relation to age, no significant differences were found, so it seems that physical activity levels remain stable throughout their university studies. This fact is relevant because, at this stage of life, people can consolidate their lifestyle, exerting a great influence on acquired habits that can be perpetuated in adult life (Práxedes, Sevil, Moreno, Del Villar, \& García-González, 2016).

Another interesting research, also in Spain, about physical and sports activities demanded by university students, shows that the rate of university students that achieve these activities is higher than sixty percent, they report that during the week they do physical activities for maintenance and improvement of health, while on weekends, individual and collective sports are the most practiced, without pursuing a competitive nature. Activities in the natural environment are becoming increasingly important during the holiday periods. Finally, the majority of students prefer to perform physical-sporting practice on their own, in a free and self-organized manner (López, Ruiz, \& García, 2010).

On the other hand, Rodríguez-Romo, Boned-Pascual and GarridoMuñoz (2009), who conducted a study with several age groups, about motives and barriers of practice for physical activity, comment that the reasons that lead people to do physical exercise or abandon it have a dynamic character and rarely reduce in a single reason. They conclude that these reasons, in the sample studied, have a playful and recreational nature, which is aimed at the maintenance and improvement of health, as well as the acquisition of a good physical appearance and, that both for the practice and for its abandonment age and gender are related. Regarding gender, men seem to practice, above all, for fun and occupation of free time, while women do it mostly to be fit. In addition, when analyzing the reasons why a part of the interviewees had never practiced physical activity or sports in their free time, it was detected that one in four people referred to the lack of time and an identical proportion, referred 
not seeing benefits or utility in practicing it.

In a work, more similar to ours, on psychometric properties, of the questionnaire Barriers to Being Active Quiz (BBAQ-21), in university students of Colombia. The results obtained confirm the use of this instrument with this type of sample, from the point of view of reliability and validity, and that can be used for studies in this population in Spanish-speaking countries, since there are few instruments in this theme (Rubio-Henao, Correa, \& Ramírez-Vélez, 2015).

For example, Ramírez-Vélez, Triana-Reina, Carrillo and RamosSepúlveda (2016), conducted a study on the perception of barriers to the practice of physical activity and abdominal obesity in university students, where more than 5,000 students participated, between 18 and 30 years old, belonging to three cities in Colombia, which was applied the above-mentioned questionnaire (BBAQ-21). They found that the barriers mentioned most often were the fear of hurting themselves and the lack of skills, followed by a lack of resources and social influence. Other barriers that were also frequently reported to justify this behavior were lack of will, lack of energy and lack of time. While Reigal, Videra, Márquez and Parra (2013), they mention physical self-concept as a relevant determinant of the reasons that prevent physical activity.

Continuing with the idea of the lack of instruments in this field Niñerola, Capdevila and Pintanel (2006), who made a factor analysis of the Self-Report Barriers for Practice Physical Exercise (ABPEF) reported by Capdevila a year earlier, comment that this questionnaire is one of the few contributions made in the Spanish language, and it formulates a certain number of statements that can be a problem or excuse to perform physical activity, originally composed of 20 items, divided into four factors: 1) Body image, related to social physical anxiety, which consists in the concern for how our body can be perceived by others; 2) Motivation, related to intrinsic personal reasons such as laziness or will power; 3) Condition, related to the difficulties due to a poor physical condition and the usual inconveniences and 4) Organization, related to the person's time availability, time and accessibility to the facilities.

The final version of the ABPEF instrument by Niñerola et al. (2006), presents good psychometric qualities, with 17 items grouped into four factors: 1) Body Image/Social Physical Anxiety, 2) Fatigue/Laziness, 3) Obligations/Lack of Time and 4) Environment/Facilities, which explain the $62.9 \%$ of the total variability of the data, reporting a high internal consistency, Cronbach's alpha $=0.85$ and a good Test-Retest reliability, with correlation coefficients higher or very close to 0.5 .

In the present study we are interested in knowing the factorial structure, and the psychometric characteristics, of the Self-Report Barriers for 
the Practice of Physical Exercise from the proposal of the above-mentioned authors, but in Mexican university athletes, with the objective that it be available to evaluate the barriers related to the practice of physical activity in our country and in other Spanish-speaking populations, since, as we have seen so far, all the work in this field focuses on university students and the population in general.

However, specifically in the Mexican population we do not find previous instruments that support the research on barriers to the practice of PA. The importance of checking the factorial structure of an instrument and the psychometric equivalence of it in different population groups justifies this investigation (Abalo, Lévy, Rial, \& Varela, 2006). Consequently, the objective of the present instrumental study (Montero \& León, 2005) was to verify the factor structure of the ABPEF and its psychometric equivalence in Mexican university athletes.

\section{Method}

\section{Participants}

The sample of 651 university students 477 men and 174 women, was obtained by means of a convenience sampling, trying to cover the representativeness of the different degrees of the Faculty of Physical Culture Sciences of the Autonomous University of Chihuahua. The age of the participants fluctuated between 18 and 36 years (mean $=20.8 \pm 2.4$ years).

The sample was randomly divided into two parts using the Statistical Package for the Social Sciences (SPSS) in its version 18.0; in order to carry out parallel studies that would corroborate and verify the results obtained (cross validation).

Subsample 1 was made up of 342 subjects. The ages fluctuate between 18 and 36 years, with a mean of 20.9 and a standard deviation of 2.4 years.

Subsample 2 was composed of 309 subjects. The ages fluctuate between 18 and 35 years, with a mean of 20.6 and a standard deviation of 2.4 years.

\section{Measure}

The ABPEF of Niñerola et al. (2006) consists of 17 items, which is respond according to a Likert scale of 0 to 10 points, where values close to 0 indicate "an unlikely reason that impede me from exercising in the next few weeks", and values close to 10 indicate a "very likely reason that impede me from practicing physical exercise." For our study, two adaptations to the version of Niñerola et al. (2006) were made: (a) the first one was to change some terms used in the items of the original version in order to use a language more appropriate to the context of Mexican culture; (B) the second consisted in applying the instrument by means of a computer (figure 1), thus allowing 
the storage of the data without previous coding, with greater accuracy and avoiding errors.

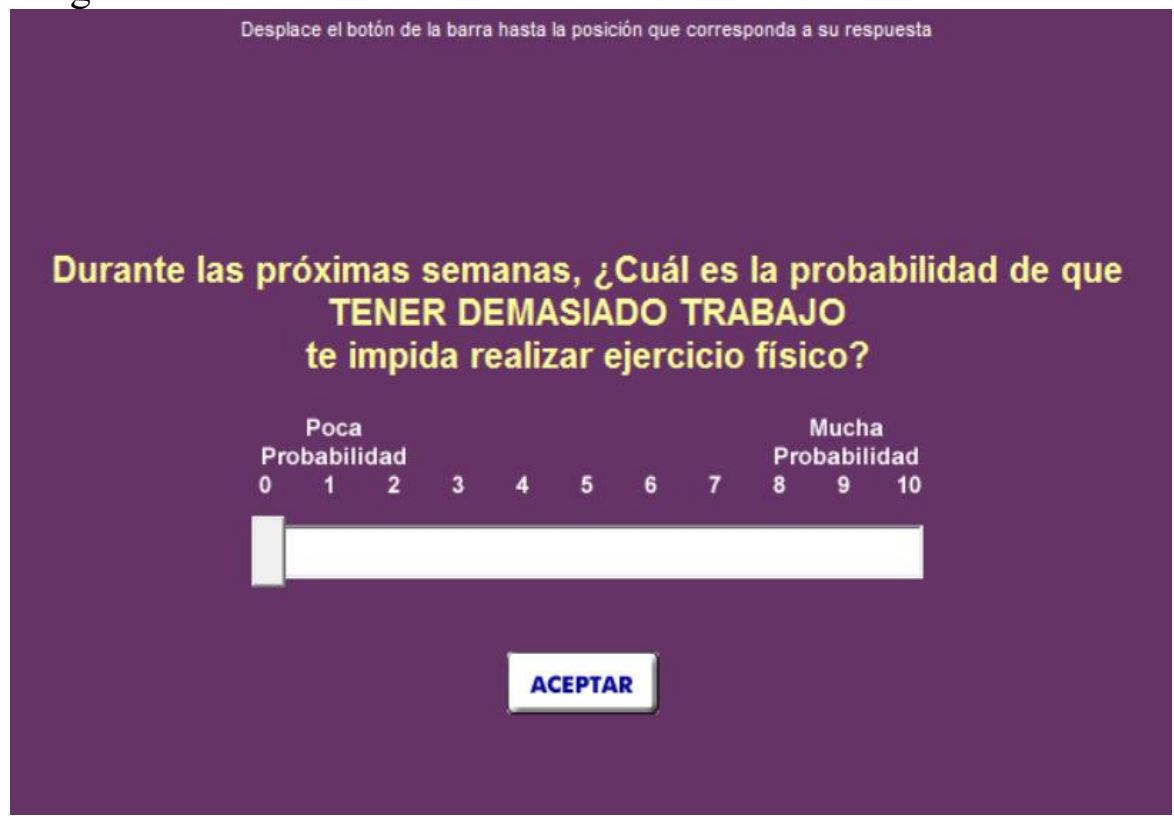

Figure 1. Sample response for questionnaire items.

\section{Procedure}

Students of the degrees offered at the Faculty of Physical Culture of the Autonomous University of Chihuahua were invited to participate. Those who agreed to participate signed the consent letter. Then, the instrument described above was applied in the laboratories of the mentioned Faculty by means of a personal computer (manager module of the instrument of the editor of typical scales of execution), in a session of approximately 30 minutes. At the beginning of each session students were given a brief introduction on the importance of the study and how to access the instrument; they were asked the utmost sincerity and they were guaranteed the confidentiality of the data obtained. Instructions on how to respond were in the first screens; before the first instrument item. At the end of the session they were thanked for their participation. Finally, the results were compiled using the results generator module of the scale editor, version 2.0 (Blanco et al., 2013).

\section{Data Analysis}

The first step in the analysis of the psychometric properties of the questionnaire was to calculate the mean, standard deviations, asymmetry, kurtosis and discrimination indexes for each item. In order to eliminate from the scale those that obtain kurtosis or extreme asymmetry or a discrimination index below 35 . 
Then, two measurement models were compared: the ABPEF-4, which responds to a four factor structure according to the original distribution of the items in the questionnaire and the ABPEF-4b that responds to the factorial structure of the previous model, eliminating the items that were not sufficiently explained by that model.

Lastly, a factor invariance analysis of the better model obtained was conducted, following the recommendations of Abalo et al. (2006), the reliability of each of the dimensions was calculated using the Cronbach's alpha (Elosua \& Zumbo, 2008; Nunnally \& Bernstein, 1995) and the omega coefficient Omega (Revelle \& Zinbarg, 2009; Sijtsma, 2009).

A confirmatory factor analysis was conducted for the first sub-sample using the software AMOS 21 (Arbuckle, 2012). The error variances were specified as free parameters. In each latent variable (factor) one of the structural coefficients associated was fixed to the value of one in order to make its scale equal to one of the observed variables (items). The maximum likelihood estimation method, following Thompson's (2004) recommendations, was conducted to compare the fit indices of several alternative models to select the best one.

In the fit model assessment, the chi-squared test, the adjusted goodness of fit index (GFI), and the root mean square error of approximation (RMSEA) were used as absolute fit indices. The adjusted goodness-of-fit index (AGFI), the Tucker-Lewis index (TLI) and the comparative fit index (CFI) were used as incremental fit indices. Chi-squared divided by degrees of freedom (CMIN/df), and the Akaike information criterion (AIC) were used as parsimony fit indices (Byrne, 2010; Gelabert et al., 2011).

\section{Results:}

Responses to all items in the total sample reflect mean scores ranging from 0.85 and 3.26, and the standard deviation in all cases is greater than 1.9 (within a range of responses between 0 and 10). Most values of asymmetry and kurtosis are within the range \pm 2.0 and \pm 4.0 , respectively, so it is inferred that the variables are reasonably adjusted to a normal distribution. Regarding discrimination indexes, all items satisfactorily discriminated with indexes above .50 (Brzoska and Razum, 2010).

\section{Confirmatory factor analysis}

The overall results of the confirmatory factor analysis in sub-sample 1 (GFI .833, RMSEA .109; CFI .868) and sub-sample 2 (GFI .861; RMSEA .095; CFI .893) for model ABPEF-4 corresponding to a structure of four factors according to the original distribution of the items within the questionnaire, indicated that the measurement model was not acceptable (Table 1). 
Table 1. Absolute, incremental and Parsimony fit indexes for the generated models. Subsamples 1 and 2.

$* \mathrm{p}<.05 ; \mathrm{GFI}=$ goodness-of-fit index; RMSEA = root mean square error of approximation; $\mathrm{AGFI}=$ adjusted goodness-of-fit index; TLI = Tucker-Lewis index; $\mathrm{CFI}=$ comparative fit index; $\mathrm{CMIN} / \mathrm{df}=$ chi-squared fit index divided by degrees of freedom; $\mathrm{AIC}=$ Akaike information criterion

\begin{tabular}{|c|c|c|c|c|c|c|c|c|}
\hline \multirow[b]{2}{*}{ Model } & \multicolumn{3}{|c|}{ Absolute Fit Indexes } & \multicolumn{3}{|c|}{$\begin{array}{l}\text { Incremental Fit } \\
\text { Indexes } \\
\end{array}$} & \multicolumn{2}{|c|}{ Parsimony Fit Indexes } \\
\hline & $\chi^{2}$ & GFI & RMSEA & AGFI & TLI & CFI & CMIN/DF & AIC \\
\hline \multicolumn{9}{|c|}{ First Factor Solution (subsample 1) } \\
\hline $\begin{array}{c}\text { ABPEF- } \\
4\end{array}$ & $567.132 *$ & .833 & .109 & .774 & .842 & .868 & 5.019 & 647.132 \\
\hline $\begin{array}{c}\text { ABPEF- } \\
4 \mathrm{~b}\end{array}$ & $207.236^{*}$ & .914 & .092 & .852 & .919 & .945 & 3.910 & 283.236 \\
\hline \multicolumn{9}{|c|}{ Second Factor Solution (subsample 2) } \\
\hline $\begin{array}{c}\text { ABPEF- } \\
4\end{array}$ & $424.433 *$ & .861 & .095 & .812 & .871 & .893 & 3.756 & 504.433 \\
\hline $\begin{array}{c}\text { ABPEF- } \\
4 \mathrm{~b}\end{array}$ & $146.670^{*}$ & .932 & .076 & .883 & .940 & .959 & 2.767 & 222.670 \\
\hline
\end{tabular}

The four factors of the ABPEF-4 model, both subsamples, explained approximately $68 \%$ of the variance. On the other hand, six of the 17 items in the first sub-sample saturated below .70 in their expected dimension (items 1 , 2, 5, 7, 14 and 17) and six in the second sub-sample (items 1, 2, 4, 5, 14 and 17). Also, high intercorrelations among the factors are observed, evidencing a not very adequate discriminant validity between them.

The overall results of the confirmatory factor analysis in the first (GFI.914, RMSEA.092; CFI.945) and second subsample (GFI.932; RMSEA.076; CFI .959), of the second model tested (ABPEF-4b) that responds to the factorial structure of the previous model (ABPEF-4), eliminating items $1,2,5$ and 14 that were not sufficiently well explained, indicated that the measurement model ABPEF-4b was better than the previous model and that its fit was acceptable (Table 1). The four factors of this model explained, in both subsamples, approximately $75 \%$ of the variance.

On the other hand, according to the results of Table 2, only one of the 13 items, in both subsamples, saturated below .70 in its predicted dimension (item 17). High intercorrelations were observed among the four factors, evidencing a not very adequate discriminant validity between them.

\section{Invariance of the factor structure between subsamples}

The fit indexes obtained (Table 3) allow to accept the equivalence of the basic measuring models between the two subsamples. Although the value of Chi-squared exceeds the required to accept the hypothesis of invariance, the $\mathrm{GFI}=.904, \mathrm{CFI}=.937$, RMSEA $=.069$ y $\mathrm{AIC}=580.541$ indexes contradict this conclusion allowing us to accept the base model invariance (unrestricted 
model).

Adding to the base model restrictions on factorial loads the metric invariance was characterized. The values shown in Table 3 allow to accept this level of invariance. The goodness of fit index (GFI .899) and root mean square error of approximation (RMSEA .068) continue to provide convergent information in this direction. Also, the Akaike Information Criterion (AIC 591.190) and Bentler comparative fit index (CFI .933) do not suffer large variations over the previous model. Using the criteria for the evaluation of the nested models proposed by Cheung and Rensvold (2002), who suggest that if the calculation of the difference of the CFI of both nested models diminish in .01 or less, the restricted model is taken for granted therefore the compliance of the factorial invariance. The difference of the CFIs obtained allows to accept the metrical invariance model. We can conclude up to this point that factorial loads are equivalent in the two subsamples.

Table 2. Standardized solutions for the confirmatory factor analysis in both subsamples.

F1 = Body Image / social physical anxiety F2 = Fatigue / Laziness F3 = Obligations / Lack of time F4 = Environment / Facilities

\begin{tabular}{|c|c|c|c|c|c|c|c|c|c|}
\hline \multirow[b]{2}{*}{ Item } & \multicolumn{4}{|c|}{ Subsample 1} & & \multicolumn{4}{|c|}{ Subsample 2} \\
\hline & & F1 F & F2 $\mathrm{F}$ & F3 F & & $\overline{\mathrm{F} 1}$ & $\mathrm{~F} 2$ & $\overline{F 3}$ & $\mathrm{~F} 4$ \\
\hline \multicolumn{10}{|l|}{$\overline{\text { Factor Loading }}$} \\
\hline $\begin{array}{l}\text { 3. Feeling uncomfortable about the way I } \\
\text { look with sports clothes }\end{array}$ & \multicolumn{5}{|c|}{.77} & \multicolumn{4}{|l|}{.71} \\
\hline $\begin{array}{l}\text { 6. Feeling that my physical appearance is } \\
\text { worse than that of others }\end{array}$ & \multicolumn{5}{|c|}{.78} & \multicolumn{4}{|l|}{.81} \\
\hline $\begin{array}{l}\text { 10. Thinking that other people are in bette } \\
\text { shape than I }\end{array}$ & \multicolumn{5}{|c|}{.89} & \multicolumn{4}{|l|}{.82} \\
\hline $\begin{array}{l}\text { 13. Thinking that others judge my physica } \\
\text { appearance }\end{array}$ & \multicolumn{5}{|c|}{.85} & \multicolumn{4}{|c|}{.84} \\
\hline $\begin{array}{l}\text { 16. Feeling embarrassed because they are } \\
\text { watching me while I exercise }\end{array}$ & \multicolumn{5}{|c|}{.65} & \multicolumn{4}{|l|}{.81} \\
\hline 8. Not being "fit" to exercise & \multicolumn{4}{|c|}{.72} & \multicolumn{5}{|c|}{.76} \\
\hline 9. Lack of will to be constant & \multicolumn{4}{|c|}{.81} & \multicolumn{5}{|c|}{.70} \\
\hline $\begin{array}{l}\text { 12. Notice tiredness or fatigue on a regular } \\
\text { basis throughout the day }\end{array}$ & \multicolumn{4}{|c|}{.75} & \multicolumn{5}{|c|}{.71} \\
\hline 4. Having too much work & \multicolumn{5}{|c|}{.70} & \multicolumn{4}{|c|}{.59} \\
\hline 7. Having too many family obligations & \multicolumn{5}{|c|}{.70} & \multicolumn{4}{|c|}{.78} \\
\hline 11. Not find time for exercise & \multicolumn{5}{|c|}{.84} & \multicolumn{4}{|c|}{.77} \\
\hline $\begin{array}{l}\text { 15. Finding myself disgusted with people } \\
\text { who exercise with me }\end{array}$ & \multicolumn{5}{|c|}{.81} & \multicolumn{4}{|c|}{.87} \\
\hline \multirow{6}{*}{$\begin{array}{l}\text { 17. The facilities or the coaches are not } \\
\text { suitable }\end{array}$} & & & & .5 & & & & & 63 \\
\hline & \multicolumn{9}{|c|}{ Factor Correlation Matrix } \\
\hline & & - & & & & - & & & \\
\hline & $\mathrm{F} 2$ & .90 & - & & & & & & \\
\hline & F3 & 67 . & .86 & - & & & .90 & - & \\
\hline & $\mathrm{F} 4$ & .86 . & .93 & .69 & - & .86 & .79 & .58 & \\
\hline
\end{tabular}


Having demonstrated the metric invariance between the subsamples, we evaluate the equivalence between intercepts (strong factorial invariance). The Indexes (Table 3) show a good adjustment of this model, evaluated independent as well as analyzed toward nesting with the metric invariance model. The difference between the two comparative indices of Bentler is .003; and the general fit index is .895 and the root mean square error of approximation is .067. Accepted then the strong invariance, the two evaluated models are equivalent toward the factorial coefficients and the intercepts.

Table 3. Goodness of fit indexes of each of the models tested in the factorial invariance. $* \mathrm{p}<.05 ; \mathrm{GFI}=$ goodness-of-fit index; NFI $=$ normed fit index; $\mathrm{CFI}=$ comparative fit index; RMSEA $=$ root mean square error of approximation; $\mathrm{AIC}=$ Akaike information criterion

\begin{tabular}{cccccccc}
\hline \multirow{2}{*}{ Model } & \multicolumn{7}{c}{ Fit indexes } \\
\cline { 2 - 8 } & $\chi^{2}$ & gl & GFI & NFI & CFI & RMSEA & AIC \\
\hline Model without restrictions & $424.541^{*}$ & 104 & .904 & .919 & .937 & .069 & 580.541 \\
Metric Invariance & $453.190^{*}$ & 113 & .899 & .914 & .933 & .068 & 591.190 \\
Strong factor invariance & $480.384^{*}$ & 123 & .895 & .908 & .930 & .067 & 598.384 \\
\hline
\end{tabular}

The factors obtained in the confirmatory factor analysis, mostly all reached values above .70 of internal consistency in both samples; demonstrating adequate internal consistency for these type of subscales, particularly if it is considered the small number of items (Table 4).

Table 4. Omega and alpha coefficient for the factors obtained

\begin{tabular}{ccccc}
\hline & \multicolumn{2}{c}{ Subsample 1 } & \multicolumn{2}{c}{ Subsample 2 } \\
\cline { 2 - 5 } Factor & $\Omega$ & $\square$ & $\Omega$ & $\square$ \\
\hline Body Image / social physical anxiety & .893 & .896 & .898 & .899 \\
Fatigue / Laziness & .805 & .776 & .767 & .741 \\
Obligations / Lack of time & .792 & .777 & .759 & .759 \\
Environment / Facilities & .646 & .663 & .727 & .706 \\
\hline
\end{tabular}

\section{Discussion}

The main objective of the study was to inquire whether or not the psychometric results proposed by Niñerola et al. (2006) replicate, for the SelfReport of "Barriers to Practice Physical Exercise" through a sample of Mexican university students using Confirmatory Factor Analysis (CFA).

Confirmatory factorial analyzes support the factorial structure of four factors: (body image, fatigue, obligations and environment) obtained by Niñerola et al. (2006) as evidencing an adequate internal consistency, particularly considering the reduced number of items in each of them. At the same time, the factors thus obtained presented, in general, adequate standardized factorial saturations, which correspond to the structure proposed for the original questionnaire, except for the elimination of items 1, 2, 5 and 14. 
On the other hand, the results of the analysis of factorial invariance between the subsamples studied indicated a high congruence between pairs of factors. This suggests the existence of strong evidence of the cross-validation of the measure and therefore of the stability of the structure, until it is proved otherwise.

In summary, the analysis of the psychometric properties of the questionnaire has shown that a four factor structure is feasible and adequate according to the psychometric requirements established when the informants are the teachers themselves.

\section{Conclusion}

The structure of four factors, based on statistical and substantive criteria, has shown adequate indicators of adjustment, reliability and validity. However, the scope of these results is limited, and it is necessary for future research to confirm the structure obtained, which will allow for more robust evidence regarding the factorial structure of the scale. Specifically, it must be demonstrated if the invariance of the structure of the scale is fulfilled by gender, age and sports discipline among others. It is therefore considered that more studies are necessary in order to corroborate or refute the data obtained in the investigations carried out so far. It is also essential to check whether the questionnaire is useful to explain the lack of motivation and adherence to the beginning and maintenance of active behavior.

\section{Acknowledgment}

Secretaría de Educación Pública-Subsecretaría de Educación SuperiorDirección General de Educación Superior Universitaria de México [Mexican Ministry of Education-Department of Higher Education-General Directorate of the University Education] (DE-13 -6894) financed this study.

\section{References:}

1. Abalo, J., Lévy, J., Rial, A., \& Varela, J. Invarianza Factorial con Muestras Múltiples. In J. Lévy (Ed.), Modelización con Estructuras de Covarianzas en Ciencias Sociales (pp. 259-278). Netbiblo: Madrid (2006).

2. Arbuckle, J. R. AMOS users guide version 21.0. Marketing Department, SPSS Incorporated: Chicago, IL (2012).

3. Blanco, H., Ornelas, M., Tristán, J. L., Cocca, A., Mayorga-Vega, D., López-Walle, J., \& Viciana, J. Editor for Creating and Applying Computerise Surveys. doi: 10.1016/j.sbspro.2013.12.105. Proc. Soc. Behav. Sci., 106, 935-940 (2013).

4. Brzoska, P., \& Razum, O. Validity Issues in Quantitative Migrant Health Research: The Example of Illness Perceptions. Peter Lang 
International Academic Publishers: New York, NY (2010).

5. Byrne, B. M. Structural Equation Modeling With AMOS: Basic Concepts, Applications, and Programming. Routledge: New York, NY (2010).

6. Castañeda-Vázquez, C., Campos, M. D. C., \& Del Castillo, O. S. Actividad Física y Percepción de Salud de los Estudiantes Universitarios. Revista de la Facultad de Medicina, 64(2), 277-284. doi: 10.15446/revfacmed.v64n2.53068 (2016).

7. Cheung, G. W., \& Rensvold, R. B. Evaluating Goodness-of-fit Indexes for Testing Measurement Invariance. doi: 10.1207/s15328007SEM0902_5. Struct Equ Modeling, 9(2), 233-255 (2002).

8. Elosua, P., \& Zumbo, B. D. Coeficientes de Fiabilidad para Escalas de Respuesta Categórica Ordenadas. Psicothema, 20(4), 896-901 (2008).

9. Gelabert, E., García-Esteve, L., Martín-Santos, R., Gutiérrez, F., Torres, A., \& Subirà, S. Psychometric Properties of the Spanish Version of the Frost Multidimensional Perfectionism Scale in Women. Psicothema, 23(1), 133-139 (2011).

10. López, M., Ruiz, F., \& García, M. E. Actividades Físico-deportivas que demandan los Universitarios. Espiral. Cuadernos del Profesorado, 3(5), 3-10 (2010).

11. Montero, I., \& León, O. Sistema de Clasificación del Método en los Informes de Investigación en Psicología. Int J Clin Health Psychol., 5, 115-127 (2005).

12. Niñerola, J., Capdevila, L., \& Pintanel, M. Barreras Percibidas y Actividad física: el autoinforme de barreras para la práctica de ejercicio físico. Revista de Psicología del Deporte, 15(1), 53-69 (2006).

13. Niñerola, J., Capdevila, L. s., \& Pintanel, M. N. Barreras Percibidas y Actividad Física: el Autoinforme de Barreras para la Práctica de Ejercicio Físico. Revista de Psicología del Deporte, 15(1), 53-69 (2006).

14. Nunnally, J. C., \& Bernstein, I. H. Teoría Psicométrica. McGraw-Hill: México (1995).

15. Organización Mundial de la Salud. Recomendaciones Mundiales de Actividad Física para la Salud. Organización Mundial de la Salud: Ginebra (2010).

16. Práxedes, A., Sevil, J., Moreno, A., Del Villar, F., \& García-González, L. Niveles de Actividad Física en Estudiantes Universitarios: Diferencias en Función del Género, la Edad y los Estados de Cambio. Revista Iberoamericana de Psicología del Ejercicio y el Deporte, 11(1), 123-132 (2016). 
17. Ramírez-Vélez, R., Triana-Reina, H. R., Carrillo, H. A., \& RamosSepúlveda, J. A. Percepción de Barreras para la Práctica de la Actividad Física y Obesidad Abdominal en Universitarios de Colombia. doi: 10.20960/nh.777. Nutrición Hospitalaria, 33(6), 13171323 (2016).

18. Reigal, R. E., Videra, A., Márquez, M. V., \& Parra, J. L. Autoconcepto Físico Multidimensional y Barreras para la Práctica Física en la Adolescencia. Apuntes Educación Física y Deportes, 111(1), 23-28 (2013).

19. Revelle, W., \& Zinbarg, R. E. Coefficients alpha, beta, omega and the glb: comments on Sijtsma. doi: 10.1007/s11336-008-9102-Z Psychometrika, 74(1), 145-154 (2009).

20. Rodríguez-Romo, G., Boned-Pascual, C., \& Garrido-Muñoz, M. Motivos y Barreras para hacer Ejercicio y Practicar Deportes en Madrid. Rev Panam Salud Pública, 26(3), 244-254. doi: 10.1590/S1020-49892009000900009 (2009).

21. Rubio-Henao, R. n. F., Correa, J. E., \& Ramírez-Vélez, R. Propiedades Psicométricas de la Versión al Español del Cuestionario "Barriers to Being Active Quiz", entre Estudiantes Universitarios de Colombia. doi: 10.3305/nh.2015.31.4.8404. Nutrición Hospitalaria, 31(4), 17081716. (2015).

22. Sijtsma, K. On the Use, the Misuse, and the Very Limited Usefulness of Cronbach's alpha. doi: 10.1007/s11336-008-9101-0. Psychometrika, 74(1), 107-120. (2009).

23. Thompson, B. Exploratory and Confirmatory Factor Analysis. Understanding Concepts and Applications. American Psychological Association: Washington, D C. (2004). 